
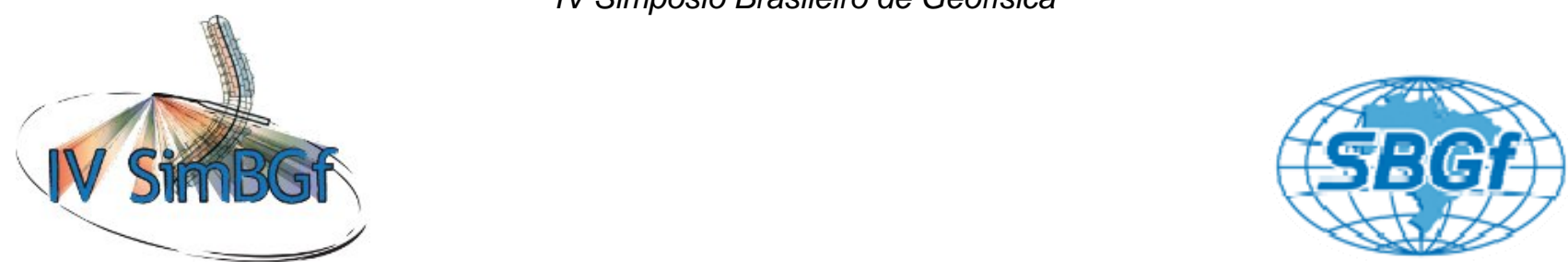

\title{
Medidas de Fluxo Geotermal Raso Em Ambientes Com e Sem Cobertura Vegetal Superficial na Cidade de Manaus-AM.
}

\author{
Gomes, P.J.B.*, SILVA, E.O.,; ARAUJO, R.L.C.:Universidade Federal do Amazonas
}

Copyright 2010, SBGf - Sociedade Brasileira de Geofísica

Este texto foi preparado para a apresentação no IV Simpósio Brasileiro de Geofísica Brasília, 14 a 17 de novembro de 2010. Seu conteúdo foi revisado pelo Comité Técnico do IV SimBGf, mas não necessariamente representa a opinião da SBGf ou de seus associados. É proibida a reprodução total ou parcial deste material para propósitos comerciais sem prévia autorização da SBGf.

\section{Introdução}

É intensamente difundido que a atividade de desmatamento provoca diversos distúrbios ambientais, em níveis local, regional e global ( OLIVEIRA et al.,2008; SOUZA et. al., 2006; ARAUJO ET AL., 2004; ARAUJO, 1999; KALNAY e MING, 2003; CHU et al., 1999; DICKINSON \& KENNEDY, 1999; LEAN at al., 1971). No entanto, para a Amazônia não há, atualmente, ainda, informações qualiquantitativas suficientes para se elaborar um modelo, plenamente aceito, o qual descreva, detalhadamente, baseando-se em dados reais (e não, apenas, em dados oriundos de modelos teóricos), a magnitude da influência da cobertura vegetal sobre o regime geotermal raso, ou seja, sobre a estrutura geotérmica nas camadas mais superficiais na Amazônia, e suas conseqüências diretas $e$ indiretas para a sociedade local. Tal conhecimento é de suma importância, face ao fato de que flutuações geotermais em tais camadas acarretam conseqüenciais diretas na biosfera terrestre como, também, ser tal zona de fundamental interesse de prospecção mineral. Assim sendo, os estudos atinentes à geotermia rasa são de efetivo interesse científico, tecnológico e social. Consideramos, portanto, ser de fundamental importância a quantificação dos parâmetros geotermais nas camadas mais superficiais na Amazônia, pois somente ter-se-á uma visão real dos efeitos das atividades de desmatamento na Amazônia, como, também, apenas será possível a elaboração de um modelo que possibilite mitigar ou eliminar tais conseqüências e, ainda, efetivamente conscientizar a sociedade local acerca dos cuidados necessários a serem tomados se, e somente se, forem quantificados, experimentalmente, os efeitos do processo de desmatamento em nosso estado. O desenvolvimento do presente projeto de pesquisa propiciará quantiqualificar o estado geotérmico atual e suas variações diurna e sazonal da temperatura na subsuperfície em dois locais diferentes, em área situada no campus da Universidade Federal do Amazonas, na cidade de Manaus (AM). Um dos locais tem cobertura e o segundo é sem cobertura vegetal

\section{Materiais e Métodos}

Foram instalados, às profundidades de $0,0 \mathrm{~m}, 0,5 \mathrm{~m}$ e $1,0 \mathrm{~m}$, em dois ambientes contíguos, um com cobertura vegetal e outro sem cobertura vegetal, ambos situados entre os blocos I (Departamento de Geociências) e G (Centro de Apoio Multidisciplinar-CAM) no setor sul do campus da Universidade Federal do Amazonas (UFAM), termômetros de termistores, que, através de fiação, são interligados ao multímetro digital localizado no Laboratório de Geofísica do Departamento de Geociências, onde são obtidas as medidas diárias de temperatura, com exceção de finais de semanas e feriados, medidas estas realizadas nos horários das $08 \mathrm{~h}$, $13 \mathrm{~h}$ e $17 \mathrm{~h}$. Após realizadas as medidas, foram determinados os valores médios mensais de temperatura para às três profundidade, nos dois ambientes, a partir dos quais foram calculados os valores de gradientes geotermal para as profundidades de $0,5 \mathrm{~m}$ e $1,0 \mathrm{~m}$. Posteriormente foram obtidos os valores de condutividade térmica com o método de calor transiente, com o aparato tipo agulho. Este aparato tipo agulha utilizado, descrito por Von Herzen \& Maxwell (1959), Smith (1973), Carvalho (1981) e Araújo (1987), consiste em uma fonte de corrente contínua, uma fina agulha hipodérmica e um multímetro digital; no interior da agulha há um fio aquecedor e um termistor localizado em seu ponto médio. Para se efetuar as medidas de condutividade térmica, a agulha é inserida na amostra a ser analisada e após ter sido atingido o equilíbrio térmico da agulha-amostra é ligada a fonte de corrente contínua, isto provoca o aquecimento da sonda cuja temperatura, registrada pelo termistor, varia com o tempo segundo (Carslaw \& Jaeger, 1959) para finalmente calcular-se o valor de fluxo geotermal para as profundidades de $0,5 \mathrm{~m}$ e 1,0 m efetuando-se o produto do valor do gradiente versos o valor da condutividade térmica

\section{Resultados e Discussões.}

A figura1 apresenta os valores de fluxo geotermal médio mensal, referentes aos meses de Janeiro a Dezembro de 2009 em dois ambientes contíguos, um sem cobertura vegetal (SV) e outro com cobertura vegetal (CV) a $0,5 \mathrm{~m}$ de profundidade. Observamos que em ambos os ambientes há uma semelhança no comportamento do fluxo geotermal ao longo do ano de 2009; para ambos os ambientes nota-se, no período compreendido entre janeiro e abril, um contínuo decréscimo nos valores de fluxo geotermal e conseqüentemente um aumento contínuo no módulo das suas magnitudes. Isto caracteriza, portanto, aumento do fluxo de calor no sentido da superfície em direção às maiores profundidades. Entre abril e junho os valores de fluxo geotermal ascendem e de junho até setembro voltam a diminuir e, ainda, de setembro a dezembro, os valores de 
fluxo geotermal tornam a ascender, destacando-se que em agosto, o valor de fluxo geotermal atingiu, para

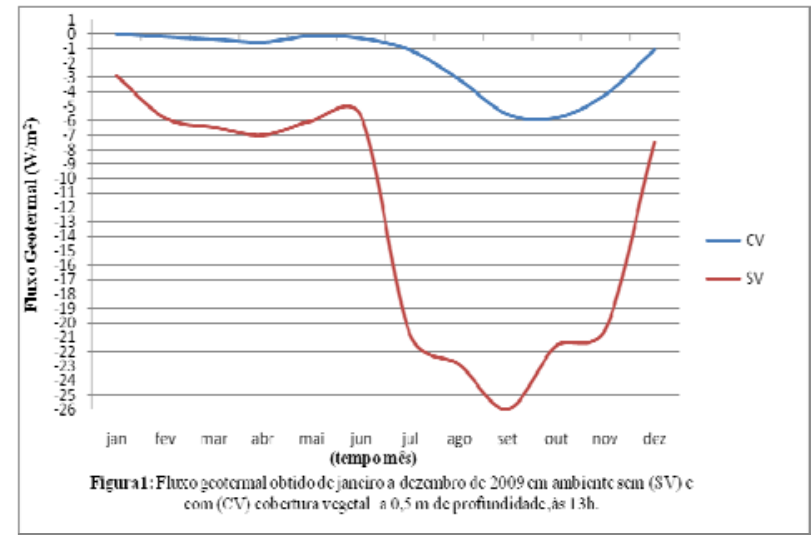

ambos os ambientes estudados, sua maior magnitude, mas com diferença significativa entre os valores de (SV) e (CV), cujo valor registrado foi de $20,42 \mathrm{~W} / \mathrm{m}^{2}$. Na figura 1 observa-se, também, que há contínuo aumento nos valores de fluxo geotermal e, conseqüentemente, diminuição em módulo da sua magnitude, de novembro até dezembro. Mas é importante notar que a diferença entre os valores de maior e menor fluxo geotermal para o ambiente SV $\left(23,0786 \mathrm{~W} / \mathrm{m}^{2}\right)$ é mais acentuado, que a diferença destes valores para ambiente CV $\left(5,74 \mathrm{~W} / \mathrm{m}^{2}\right)$. Isto é explicado em virtude do ambiente (SV) ser mais susceptível às variações climáticas diurnas e sazonais, dado a falta de proteção superficial causada pelo desmatamento do local em questão.

As mudanças nos módulos das magnitudes de fluxo geotermal observadas durante 0 ano estudado ocorrem em virtude de que para a Amazônia o período compreendido entre janeiro e junho é considerado um período de alta pluviometria, logo, parte do calor oriundo da radiação solar incidente na superfície terrestre é atenuado em virtude de maior nebulosidade, que tende a refletir parte desta radiação solar incidente e por parte deste calor ser consumido como calor latente no processo de evaporação, e o período compreendido entre julho e dezembro para a Amazônia é considerado o período seco, com baixa pluviometria e nebulosidade e, conseqüentemente, maior índice de radiação solar incidente na superfície terrestre.

Os valores de condutividade térmica, para ambos ambientes estudados, apresentaram diferença significativa. No período considerado chuvoso (de janeiro a junho), o valor medido foi de $0,78 \mathrm{~W} / \mathrm{m} .{ }^{\circ} \mathrm{C}$, enquanto que no período considerado seco (de julho a dezembro ), o valor medido foi de $1,57 \mathrm{~W} / \mathrm{m} .{ }^{\circ} \mathrm{C}$. Os dois ambientes estudados apresentam pequena diferença de composição entre os solos, em virtude do conteúdo de matéria orgânica no solo do ambiente com cobertura vegetal (CV).

É importante mencionar que durante todo $\mathrm{o}$ ano estudado, à profundidade de $0,5 \mathrm{~m}$, a magnitude dos valores de fluxo geotermal no ambiente (SV) é superior aos valores referentes ao ambiente (CV). Tal comportamento é observado mesmo nos períodos de altas nebulosidade e pluviosidade, conseqüentemente, de baixo índice de radiação solar incidente na superfície terrestre. Assim sendo, a esta profundidade, o fluxo geotermal registrado no ano de estudo esteve, sempre, fluindo da superfície para o subsolo, o que é ilustrado na figura 1 pelo caráter negativo de todos os valores de fluxo geotermal para ambos os ambientes.

A figura 2 mostra os valores de fluxo geotermal médio mensal, obtidos de Janeiro a Dezembro de 2009 em dois ambientes contínuos, um sem cobertura vegetal (SC) e outro com cobertura vegetal (CV) a 1,0 m de profundidade. Observamos em ambos os ambientes que, entre janeiro e junho, o módulo das magnitudes dos valores de fluxo geotérmico exibem um contínuo decréscimo até abril, com posterior acréscimo até junho. É importante destacar que para este período, mesmo com decréscimo no modulo da magnitude do fluxo geotermal, o sentido de fluxo geotermal é do subsolo para a superfície do local estudado; este comportamento no sentido do fluxo geotermal é indicado pelo caráter positivo dos valores de fluxo observados na figura 2. É, também, importante destacar que no ambiente (SV) se observa para este período, ainda, uma inversão no sentido do fluxo geotermal no mês de abril, representado pelo caráter negativo dos valores deste parâmetro geofísico.

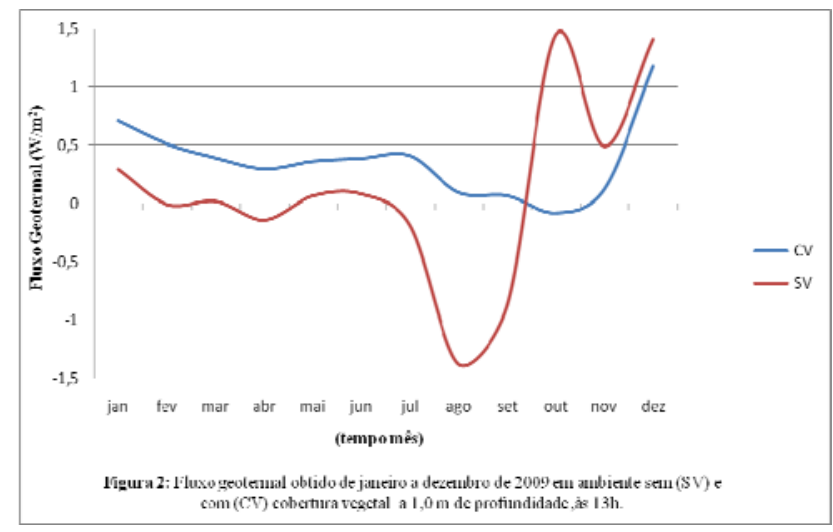

No mês de agosto se observa a inversão no sentido do fluxo geotermal e um aumento abrupto na magnitude dos valores de fluxo geotermal para o ambiente (SV) em relação ao ambiente (CV), em virtude deste ambiente receber maior quantidade de energia, pois sua superfície está desprotegida, o que produz um gradiente geotérmico com maior magnitude. Outro fato importante, observado ainda na figura 2, é que o único momento em que se observa a inversão no sentido do fluxo geotermal no ambiente (CV) é no mês de outubro, mês este que para a Amazônia é caracterizado, ratificamos, por alta radiação solar incidente na superfície terrestre e baixa pluviometria. Neste mesmo período de outubro, para o ambiente (SV), é registrado uma inversão abrupta no sentido do fluxo geotermal a 1,0 $\mathrm{m}$ de profundidade. Isto ocorre em virtude do fato ressaltado anteriormente, ou seja, de que este período, na Amazônia, é caracterizado por elevados índice de radiação solar incidente na superfície terrestre e, também, a ocorrência de chuvas esporádicas, que tendem 
a reduzir bruscamente os efeitos do calor oriundo da radiação solar na superfície e gerar inversão no sentido do fluxo geotermal a 1,0 $\mathrm{m}$ de profundidade.

É importante ressaltar que o intervalo entre o valor de maior fluxo geotermal e o valor de menor fluxo geotermal para o ambiente (SV) é mais acentuado, mesmo a $1,0 \mathrm{~m}$ de profundidade, pois a diferença para o ambiente (CV), que foi de $0,792 \mathrm{~W} / \mathrm{m}^{2}$, para o ambiente $(\mathrm{CV})$, de 2,844 $\mathrm{W} / \mathrm{m}^{2}$, em virtude do ambiente (SV) ser mais susceptível às variações climáticas diurnas e sazonais, dado a falta de proteção superficial causada pelo desmatamento do local em questão.

A partir de novembro até dezembro se observa comportamentos semelhantes, nas magnitudes e sentidos dos valores de fluxo geotermal para ambos os ambientes (SV) e (CV), pois este período, na Amazônia, é caracterizado por um período de transição do período seco para o período chuvoso. Também é importante ressaltar que a magnitude destes valores para o ambiente (SV) é superior para o período de novembro a dezembro.

\section{Conclusões}

Em base no acima exposto é possível concluir que durante todo $\mathrm{o}$ ano estudado os valores de fluxo geotermal a $0,5 \mathrm{~m}$ de profundidade exibem maiores magnitudes no ambiente (SV).

No período de maior incidência de radiação solar na Amazônia, a 0,5 $\mathrm{m}$ de profundidade, é registrado valores de elevada magnitude de fluxo geotermal, para ambos os ambientes (CV) e (SV), mas com uma diferença entre o valor (SV) e (CV) de 20,422 W/m².

Durante todo o ano estudado, a $0,5 \mathrm{~m}$ de profundidade, o fluxo geotermal para os dois ambientes (SV) e (CV), mesmo com variações em suas magnitudes, exibem apenas um sentido de fluxo geotermal, da superfície para a subsuperfície.

No período que na Amazônia é caracterizado por período baixo índice de radiação solar incidente na superfície terrestre, em virtude da alta nebulosidade que tende a refletir parte da radiação e de alta pluviometria, pois parte deste calor é consumido como calor latente no processo de evaporação, ambos os ambientes (SV) e (CV) exibem suas menores magnitudes nos valores de fluxo geotermal.

De janeiro a junho do ano estudado, a $1,0 \mathrm{~m}$ de profundidade, no ambiente (CV), mesmo com a diminuição da magnitude do fluxo geotermal, o sentido de fluxo é do subsolo para a superfície do local estudado.

Durante o ano estudado, a $1,0 \mathrm{~m}$, ao contrário de $0,5 \mathrm{~m}$ de profundidade, se observa a inversão no sentido do fluxo geotermal em ambos os ambientes (SV) e (CV).

No período de janeiro a junho, para o ambiente (CV), a $1,0 \mathrm{~m}$ de profundidade, mesmo com a diminuição da magnitude do fluxo geotermal, o fluxo é no sentido do subsolo para a superfície do local estudado.

No período caracterizado na Amazônia por maior incidência de radiação solar e baixa pluviometria, a 1,0 m de profundidade, chuvas esporádicas podem alterar o sentido do fluxo geotermal e que o ambiente (SV) é mais susceptível a variações na magnitude e no sentido deste fluxo.

No mês de agosto se observa a inversão no sentido do fluxo geotermal e um aumento abrupto na magnitude do valor de fluxo geotermal para o ambiente (SV), em relação ao ambiente (CV), em virtude deste ambiente receber maior quantidade de energia, pois sua superfície está desprotegida, o que provoca mudanças no gradiente geotérmico com maior magnitude e negativo.

\section{Agradecimentos}

A fundação de Amparo a Pesquisa do Estado do Amazonas - FAPEAM.

\section{Referências}

ARAÚJO, R.L.C.,SILVA., CARVALHO, JS., MONTEIRO, I. B. Influência Ambiental Sobre a Estrutura Geotermal Rasa. Revista de Geofísica, v.22, 33-44.2004.

ARAÚJO, R.L.C. Contribuição da Geotermia Rasa aos Estudos Ambientais. EDUA ed., Manaus (AM), 86p.,1999. ASTIER AE. 1975. Geofísica Aplicada a la Hidrogeologia. Madrid. Paraninfo. P. 344.

BECK AE. 1965. Techniques of Measuring Heat Flow on Land. In: Lee W. Terrestrial Heat Flow. Washington. American Geophysical Union.

BOWEN R. 1966. Paleontemperature Analysis. Methods in Geochemistry and Geophysics. Elsevier. Publishing, p. 265.

CARSLAW HS and JAEGER JC. 1959. Conduction of Heat in Solids. $2^{\text {a }}$ ed. Oxford. Clarendon Press. p. 527.

CHU,P.S.; YU, Z.P. \&MHASTENRATH, S. Change concurrent with has it gone? Bull. Amer. Meteorol. Soc., 75, 579-583,1999.

DICKINSON, R.E AND KENNEDY, P. Impacts on regional climate of Amazon deforestation. Geophys. Res Letters, 1947-1950, 1999.

KALNAY, E. AND KAI, MING. Impact of Urbanization and Land-Use Change on Climate. Nature, v.23, 528-531, 2003.

LEAN, J.; BUNTON, C.B.; NOBRE, C.A. \& ROWNTREE, P.R. THE Simulated impact of Amazonian deforestation on climate using measured ABRACOS vegetation characteristics. Amazonian Deforestation and Climate. Editado por Gash, J.H.C.; Nobre, C.A.; Roberts, J.M. \& Victória, R.L..John Wiley \& Sons, England, 549576, 1996.

OLIVEIRA, F. N. M., ARAÚJO, R. L. C., CARVALHO, J. S., COSTA, S.S. Determinação da variação no Microclima de Manaus-AM, Por atividades Antropogênicas e Modulações Climáticas Naturais.. Revista Acta Amazônica., v.38, p.687 - 700,2008.

ROY, .F.R.; BLACKWELL, D.D \& DECKER, E.R. Continental heart flow. In: Robertson, R. The Nature of the Soil. New York. Mc Graw-Hill. 506-543, 1971.

SOUZA, J.R. S., MAKINO, M., ARAUJO, R. L. C., COHEN, J. C. P., PINHEIRO, F. M. A. Thermal Properties and heat fluxes in Soils Under Forest and Pasture in Marabá, PA, Brazil. Revista Brasileira de Meteorologia., v.21, p.89-103,2006. 
Medidas de fluxo Geotermal na cidade de Manaus AM. 